\title{
AVALIAÇÃO DO DESEMPENHO DE SISTEMAS ESTRUTURAIS DE EDIFICACCOES HABITACIONAIS EM JUAZEIRO DO NORTE COM BASE NA NBR 15575/2013
}

\author{
LEITE, IANE MOTA LANDIM \\ Profissão: Engenheira civil \\ Instituição: UFCA \\ Ceará, Brasil \\ e-mail: ianemotal@hotmail.com
}

\author{
BORGES, ANA VERONICA GONCALVES \\ Profissão: Professora \\ Instituição: UFCA \\ Ceará, Brasil \\ e-mail: ana.borges@ufca.br
}

\author{
CIRINO, MIGUEL ADRIANO GONÇALVES \\ Profissão: Professsor e aluno de graduação \\ Instituição: URCA \\ Ceará, Brasil \\ e-mail: miguel.goncalves@urca.br
}

\begin{abstract}
RESUMO
O nível desempenho dos sistemas estruturais de edificações habitacionais é diretamente relacionado à qualidade durante as fases de projeto, execução e uso e, para garantir segurança e eficiência nestas etapas, os edifícios devem apresentar um nível de desempenho mínimo, conforme recomendações da norma de desempenho habitacional brasileira (ABNT NBR 15575). A pesquisa envolve qualificação de pontos de inconformidade com os critérios mínimos requeridos na NBR 15575/2013 e avaliação das manifestações patológicas que acometem estas edificações. Para tal, aplicou-se em cinco obras, em fase de execução, um questionário com o intuito de diagnosticar o conhecimento dos construtores, quanto às recomendações mínimas e a aplicação destas nos novos empreendimentos e, para a avaliação das manifestações patológicas, levantou-se conforme observado pela equipe técnica das obras. Os resultados apontam um bom nível de conhecimento acerca das recomendações, apenas os tópicos relativos à resistência dos elementos de concreto armado, em situação de incêndio, apresentam indicadores inferiores às especificações mínimas requeridas. Então, pode-se concluir que os procedimentos adotados pelas equipes técnicas, durante o projeto e execução das unidades habitacionais, indicam base satisfatória quanto ao desempenho mínimo dos seus sistemas estruturais.
\end{abstract}

Palavras-chave: Desempenho habitacional. NBR 15575. Sistemas estruturais. Inspeção visual.

\begin{abstract}
The performance level of the structural systems of residential buildings is directly related to quality during the design, execution and use phases and, in order to guarantee safety and efficiency in these stages, buildings must present a minimum level of performance, according to the recommendations of the standard of housing performance (ABNT NBR 15575). The research involves qualification of points of nonconformity with the minimum criteria required in NBR 15575/2013 and evaluation of pathologies that affect these buildings. To this end, a questionnaire was applied in five works, in the execution phase, in order to diagnose the knowledge of the builders, with respect to the minimum recommendations and their application in the new projects and, in order to evaluate the pathologies, observed by the technical team of the works. The results indicate a good level of knowledge about the recommendations, only the topics related to the resistance of the elements of reinforced concrete in a fire situation, present indicators below the minimum specifications required. Therefore, it can be concluded that the procedures adopted by the technical teams during the design and execution of housing units indicate a satisfactory basis for the minimum performance of their structural systems.
\end{abstract}

Keywords: Housing performance. NBR 15575. Structural systems. Visual inspection. 


\section{INTRODUÇÃO}

Durante grande parte da história da construção civil, a atenção em garantir que as habitações mantivessem seus componentes funcionando plenamente inexistiu, não havendo como mensurar por quanto tempo determinados elementos de uma edificação seriam capazes de se manterem eficientes (BORGES, 2008). Com a priorização ao conforto do usuário, surge a necessidade de quantificar e qualificar o desempenho das habitações, termo que se relaciona ao comportamento de uma edificação e seus sistemas durante o uso (ABNT, 2013).

A partir da implementação da ABNT NBR 15575/2013 (Edificações Habitacionais - Desempenho), espera-se a elevação da qualidade dessas edificações no Brasil, de forma a garantir maior segurança e conforto aos usuários, além de estímulo à produção de empreendimentos com maior controle de qualidade durante o projeto e execução, o que agrega valor aos imóveis produzidos (CBIC, 2013). Por se tratar de uma norma relativamente recente, e tendo em vista que a construção civil requer certo tempo para se adequar a novas propostas, há a possibilidade de que suas recomendações ainda não sejam plenamente aplicadas nas edificações residenciais brasileiras.

Este artigo apresenta um estudo de caso realizado no município de Juazeiro do Norte, CE, que consiste no levantamento de dados acerca do desempenho de sistemas estruturais em concreto armado de edificações habitacionais que se instalam no município, com o intuito de verificar o nível de adequação desses empreendimentos às recomendações de desempenho.

\section{REFERENCIAL TEÓRICO}

\subsection{Edificações Habitacionais - Desempenho}

A nível internacional, desempenho é estabelecido através da definição de requisitos, critérios e métodos de avaliação, de forma a permitir sua mensuração quantitativa e qualitativa. Normas de desempenho são complementares às normas prescritivas, traduzindo as necessidades dos usuários em critérios e requisitos, sem substituir as demais recomendações relacionadas (ABNT, 2013).

Segundo a Câmara Brasileira da Indústria da Construção, CBIC (2013), a aplicação dessa norma busca tanto reduzir as incertezas relacionadas a critérios subjetivos em perícias como estimular a redução da concorrência predatória e instrumentar o Código de Defesa do Consumidor. Considera-se que a avaliação dos sistemas construtivos representa avanço para todos os setores da construção civil.

A implementação do conceito de desempenho na construção civil retrata o estímulo à análise dos fins a serem cumpridos pela obra, prescrevendo requisitos que ela deverá atingir durante o seu uso. Independentemente do tipo de material ou técnica escolhida para a execução de um sistema, o resultado obtido deve satisfazer os critérios exigidos para atender ao usuário.

Para garantir que o nível de desempenho dos sistemas estruturais de uma edificação seja atingido, é necessário que o projeto e a execução estejam adequados aos requisitos estabelecidos tanto pela norma desempenho quanto pelas normas prescritivas relacionadas ao tipo de estrutura empregada.

\subsection{Vida Útil e Manutenção Predial}

Vida útil de uma estrutura de concreto refere-se ao tempo em que suas características se mantêm, sem que haja intervenções significativas, desde que sejam atendidos os requisitos de uso e manutenção prescritos por projetista e construtor, além de execução de eventuais reparos decorrentes de danos acidentais (ABNT, 2014).

Segundo a norma desempenho, a vida útil de projeto representa o valor real de tempo da vida útil de uma habitação, definida previamente em projeto. Além de considerar a qualidade da obra como um todo, a ABNT NBR 15575/2013 estabelece que outros fatores também devem ser considerados, como os efeitos causados pela utilização, limpezas e manutenções da edificação, bem como das ações da natureza e efeitos gerados pela vizinhança. De acordo com a ANBT NBR 8681/2003, os elementos estruturais de uma edificação devem ter vida útil no mínimo igual a 50 anos.

Manutenção predial envolve o conjunto de ações necessárias para conservar ou restaurar a capacidade funcional da construção e seus sistemas, para permitir que o usuário permaneça com suas necessidades atendidas, e garantir sua segurança (CBIC, 2013).

Ao definir a vida útil de projeto, leva-se em consideração que cada sistema deverá passar por intervenções que permitam-no manter seu funcionamento pleno, de forma a prolongar a vida útil da habitação (BORGES, 2008). 
Para permitir que a vida útil de projeto seja atingida, é imprescindível que seja elaborado o Manual de Uso e Operação da Edificação, em consonância com a ABNT NBR 14037. No ato da entrega do empreendimento, o usuário deve ser informado sobre a importância de realizar todas as ações relativas à manutenção, para permitir a eficiência da gestão predial.

\subsection{Manifestações Patológicas}

O termo "Patologia" foi introduzido na construção civil com uma variação do seu emprego na medicina, em que alterações estruturais e funcionais de um sistema são provocadas por doenças, cujas causas são provenientes de mecanismos específicos (FRANÇA et al., 2011). Analogamente, qualquer componente de uma edificação pode ter seu desempenho comprometido devido ao surgimento de manifestações patológicas, geradas por falhas no projeto, execução, uso ou manutenção de determinados componentes do sistema.

A existência de manifestações patológicas em elementos estruturais de uma edificação pode indicar que esta não será capaz de atingir o desempenho requerido para garantir sua eficiência durante seu uso e operação. O surgimento de problemas patológicos mais recorrentes em estruturas de concreto armado se relacionam não só a falhas no emprego dos materiais constituintes do concreto, como inadequação ao grau de agressividade ambiental e problemas na dosagem, como também a falhas na execução, como imperfeições no adensamento e acompanhamento ineficiente do processo de cura. Também são relevantes os problemas construtivos provenientes de utilizações não previstas para a estrutura, como a aplicação de sobrecargas que não constam em projeto.

Prevenir o surgimento de manifestações patológicas é imprescindível para permitir que o desempenho dos sistemas estruturais permaneça adequado às necessidades dos usuários. Elementos estruturais que apresentam esse tipo de falha podem comprometer desde o conforto do habitante até a estabilidade da edificação.

\section{METODOLOGIA}

A pesquisa se trata de um estudo de caso, voltado para a análise do desempenho dos sistemas estruturais de edificações habitacionais em execução no município de Juazeiro do Norte - Ceará.

Ao total foram analisadas cinco edificações no período de dezembro de 2018 a maio de 2019, todas são habitações multifamiliares (três unidades com dois pavimentos e duas unidades com 4 pavimetos), com sistema estrutural completamente composto por concreto armado, paredes de alvenaria em bloco cerâmico e revestimento externo em cerâmica e interno com pintura. As edificações ficam localizadas em bairros residenciais, onde há uma baixa movimenta de veículos. A metodologia aplicada na pesquisa obedeceu o esquema apresentado na Figura 1.

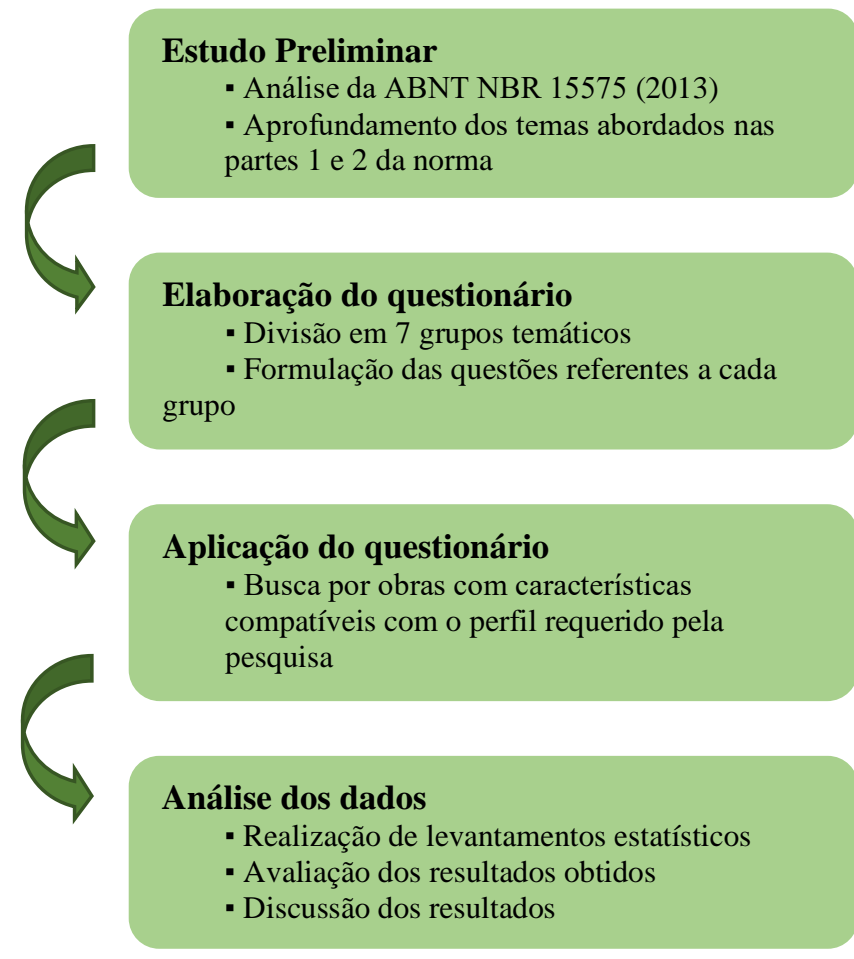

Figura 1 - Atividades desenvolvidas durante a pesquisa 
Concluidas as etapas de Estudo preliminar, Elaboração do questionário, inicou-se a aplicação de um questionário nas cinco obras avalaidas, em fase de execução, onde teve-se como base o cumprimento dos requisitos da ABNT NBR $15575 / 2013$ com ênfase nos sistemas estruturais.

Os questionários foram entregues aos responsáveis técnicos pelas obras (Engenheiros, técnicos e encarregados pelos serviços), não pode-se obter diretamente os dados pela técnica de entrevista, visto que o acesso à três das cinco obras sera restrito, assim, optou-se por uniformizar a obtenção dos dados por qplicação de questionários. Vale salientar que os dados obtidos decorrem das informações obtidas, tentando-se relacionar, na medida do possível, com as informações observadas durantes as visitas técnicas. Os temas abordados no questionário são:

- Materiais empregados para execução dos elementos estruturais;

- Durabilidade e manutenibilidade dos sistemas estruturais;

- Impacto ambiental gerado pela obra;

- Estanqueidade à água dos elementos estruturais (águas pluviais, águas de uso interno na edificação ou umidade do solo)

- Resistência da estrutura em situação de incêndio;

- Requisitos específicos dos sistemas estruturais;

- Manifestações patológicas no concreto armado.

Durante a pesquisa, optou-se também pela realização de levantamento sobre as manifestações patológicas que acometem as estruturas de concreto armado dessas edificações, por meio de perguntas feitas à equipe técnica dos empreendimentos, além da indicação de medidas corretivas desses problemas ou minimizar seus efeitos.

A avaliação das manifestações patológicas seguiu a memsa metodologia anterior, com aplicação de questonários com a equipe técnica das obras, porém, com foco na descrição da manifestação patológica observada e o quantitavo referente à sua incidência.

\section{RESUlTAdOS E DISCUSSÕES}

Diante dos dados coletados, tem-se que uma parcela considerável das recomendações de desempenho habitacional é aplicada às edificações em execução no município estudado.

\subsection{Materiais utilizados na execução dos elementos estruturais}

No geral, os materiais utilizados para a execução dos sistemas estruturais tiveram seu desempenho comprovado pelos fabricantes. A certificação de qualidade foi realizada por meio do requerimento de laudos técnicos tanto do aço como do concreto, bem como mediante a apresentação de certificado de qualidade dos materiais e à submissão de ensaios de corpos de prova de concreto usinado. Destaca-se também a preocupação das equipes técnicas com o controle tecnológico do concreto utilizado na composição dos elementos estruturais.

Em todas as obras foi relatado que os projetistas especificaram as características dos materiais que devem ser adquiridos para a execução da obra, a fim de atender a vida útil estabelecida em projeto. A responsabilidade quanto à fiscalização da qualidade dos materiais utilizados reflete na atenção dos construtores em garantir que sejam produzidos elementos estruturais cujas características sejam condizentes com as especificações de projeto e tenham a durabilidade esperada. Cerca de $80 \%$ dos casos, não foi apontada a existência de riscos previsíveis relacionados à execução da obra, como a presença de aterro sanitário no local, ou existência de agentes agressivos no solo, por exemplo.

\subsection{Durabilidade e manutenibilidade dos sistemas estruturais}

Em relação à vida útil de projeto estabelecida para os sistemas estruturais, tem-se que sua quantificação não estava exposta em memorial de cálculo ou nos projetos em $60 \%$ das obras avaliadas.

A Figura 1 relaciona itens que devem ser constatados em manuais de uso, operação e manutenção de edificações residenciais com a frequência em que estes serão abordados nos manuais das edificações estudadas. De acordo com a ABNT NBR 15575-2/2013, esses temas devem ser contemplados na elaboração do referido documento a fim de garantir a durabilidade dos sistemas estruturais durante sua vida útil. 


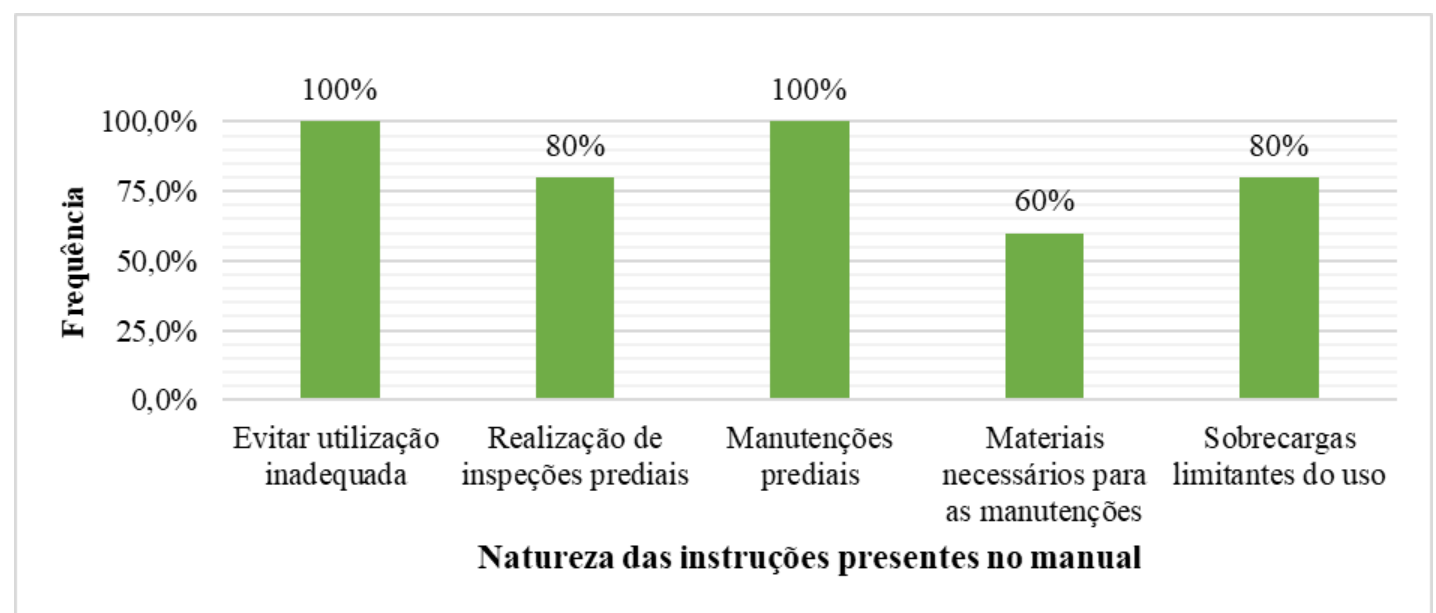

Figura 2 - Conteúdo do manual de uso, operação e manutenção das edificações

Observa-se que as instruções básicas de manutenção serão abordadas nos manuais de todas as edificações estudadas, que são as recomendações gerais para prevenção de falhas e acidentes decorrentes de utilização inadequada, bem como a periodicidade, forma de realização e forma de registro das manutenções. Em todas as edificações envolvidas no estudo, os responsáveis pela execução relataram que até a presente fase da obra não foram realizadas manutenções nos sistemas estruturais.

\subsection{Impacto ambiental gerado pela obra}

Nas obras avaliadas durante o estudo, tem-se que a maioria dos procedimentos sugeridos pela norma de desempenho para promover a redução do impacto ambiental gerado pela instalação de edificações habitacionais são de fato aplicados. A Figura 3 associa medidas que contribuem para a redução do impacto ambiental gerado pela implantação da obra com a frequência de sua implantação nos canteiros envolvidos na pesquisa.

A preocupação mais recorrente dos construtores locais baseia-se em garantir que o consumo de água durante a obra seja minimizado, reduzindo o desperdício desta. Esse resultado representa não só a responsabilidade com o consumo consciente desse recurso, uma vez que, ao garantir que não haja gasto superior ao estritamente necessário, são geradas reduções significativas nos custos globais da obra. Logo, a adoção de medidas que visam reduzir o consumo de água durante a obra representa tanto a redução do impacto ambiental como também implica em ganhos financeiros.

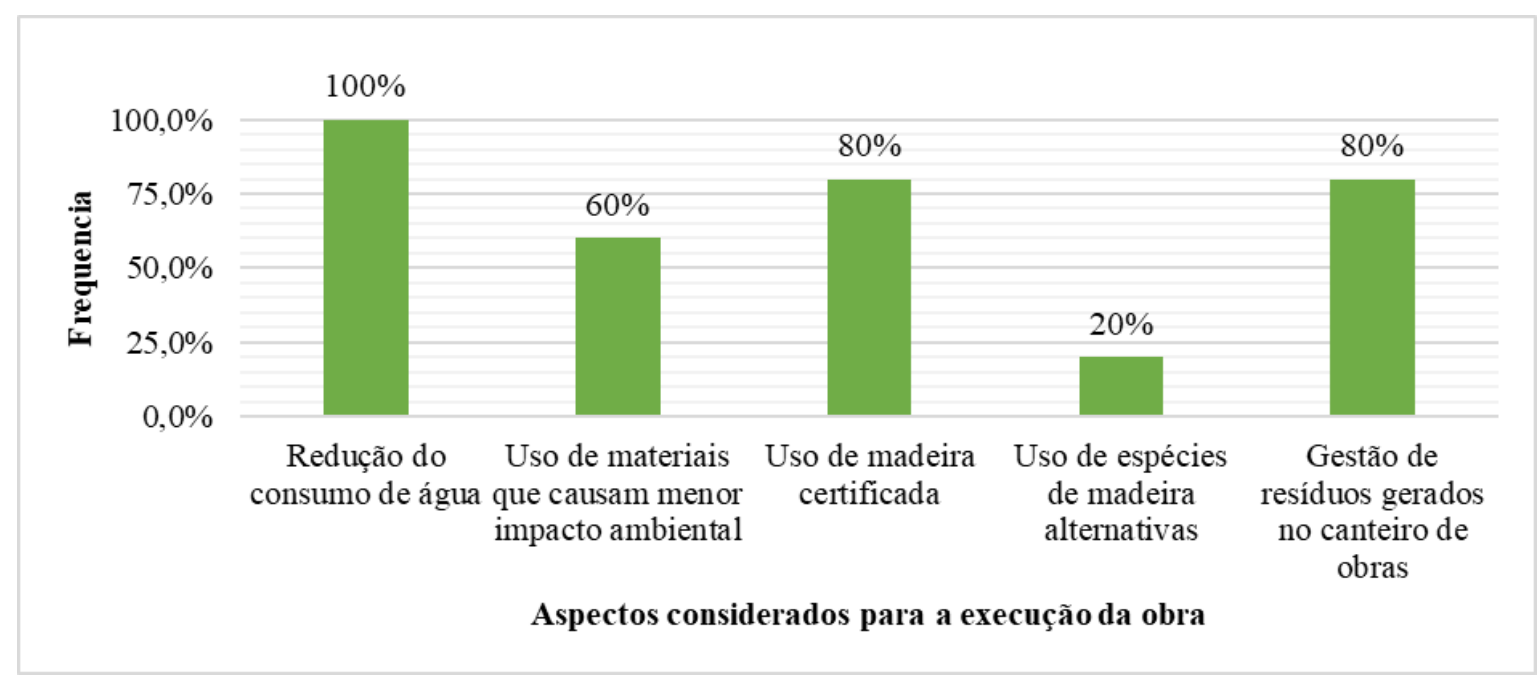

Figura 3 - Medidas adotadas para redução de impacto ambiental

No que diz respeito à seleção dos materiais utilizados para compor os sistemas estruturais, tem-se que a atenção à seleção de materiais que causem menor impacto ambiental encontra-se abaixo do nível esperado. Os construtores 
geralmente optam por adquirir materiais que atendem às especificações técnicas dos projetistas e cujo benefício financeiro é superior. Esses dados demonstram que há empenho por parte dos construtores em reduzir a quantidade de entulho depositado no meio ambiente, porém, percebe-se que ainda é necessário investir em métodos que permitam a reutilização de materiais.

\subsection{Segurança em situação de incêndio}

Apenas uma das obras consultadas teve o Tempo Resistência Requerido ao Fogo (TRRF) estabelecido e informado no projeto estrutural. Nesse caso, verificou-se que o valor atribuído é condizente com as recomendações da referida norma, de acordo com a altura total da edificação e profundidade do seu subsolo. Nos demais casos, os responsáveis técnicos indicaram que essa informação não constava no memorial de cálculo.

Em relação à energia calorífica suportada pelas edificações, tem-se que a carga de incêndio não foi estabelecida em nenhuma das obras consultadas. Consequentemente, as equipes técnicas desconheciam a resistência da estrutura à energia gerada pela queima dos materiais que compõem os diversos sistemas da edificação, como por exemplo forros, revestimentos e esquadrias. Esses dados mostram que, de forma geral, não é possível reconhecer se as estruturas foram dimensionadas de forma a garantir os requisitos mínimos de desempenho em situação de incêndio, com base nas recomendações da ABNT NBR 15575-2/2013 e ABNT NBR 14432.

Também foi realizado o levantamento acerca dos principais itens que devem estar presentes em uma edificação residencial para facilitar a fuga dos usuários durante um incêndio, dificultar a propagação do fogo e permitir a sua extinção. A frequência com que esses dispositivos foram observados nas edificações estudadas ou estão com instalação prevista está apresentada no Figura 4.

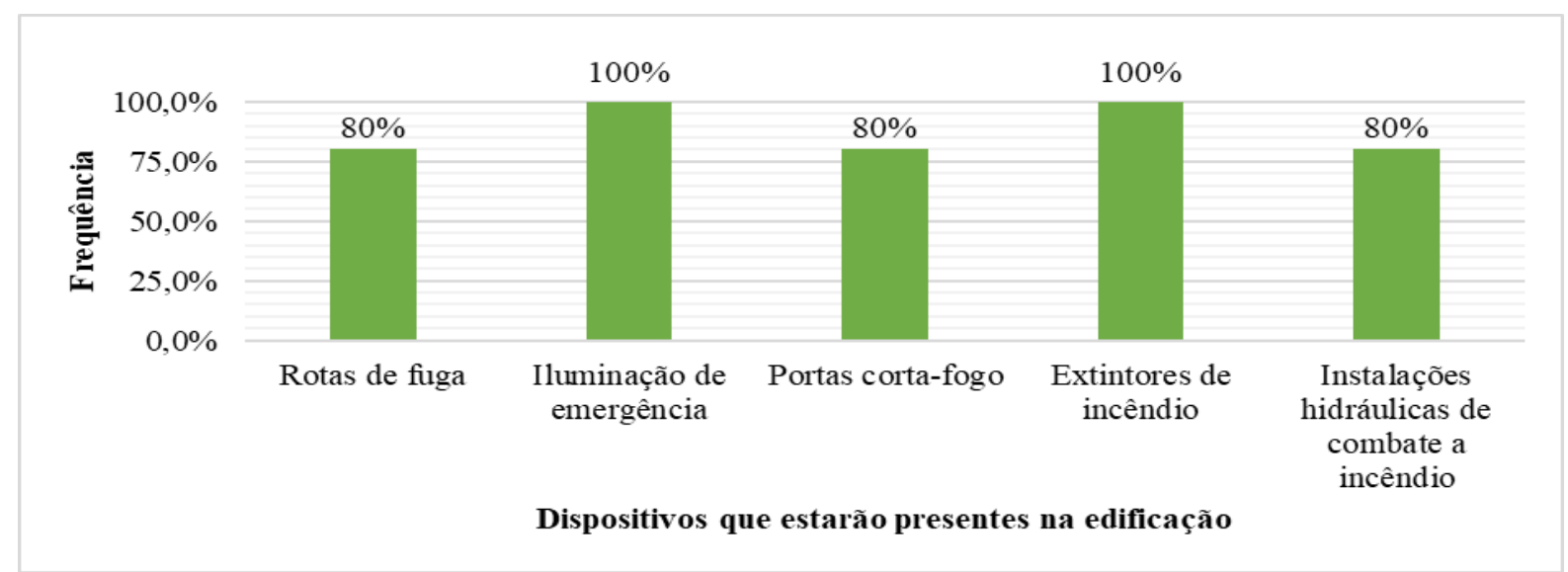

Figura 4 - Dispositivos de segurança contra incêndio presentes nas edificações

Observa-se que há elevada atenção dos projetistas e construtores com relação à aplicação desses elementos nas edificações, uma vez que $60 \%$ das habitações contarão com todos os dispositivos citados. Além disso, cada item abordado estará presente em pelo menos $80 \%$ delas.

Todas as obras consultadas terão pelo menos um recurso para promover a evacuação do local (sistema de iluminação de emergência), e um de combate ao fogo (extintores de incêndio). De forma geral, garantir a existência de espaço adequado para esse tipo de operação não foi uma precaução considerada durante a fase de projeto.

\subsection{Estanqueidade à água dos elementos estruturais (águas pluviais, águas de uso interno na edificação ou umidade do solo)}

Para a avaliação da estanqueidade à água, foram abordadas as medidas que visam impedir o contato tanto das águas pluviais como daquela de uso interno da edificação, bem como da umidade do solo. A Figura 5 ilustra a proporção em que são aplicadas, nas obras em estudo, as medidas que visam reduzir a infiltração e a presença de umidade nos elementos estruturais. 


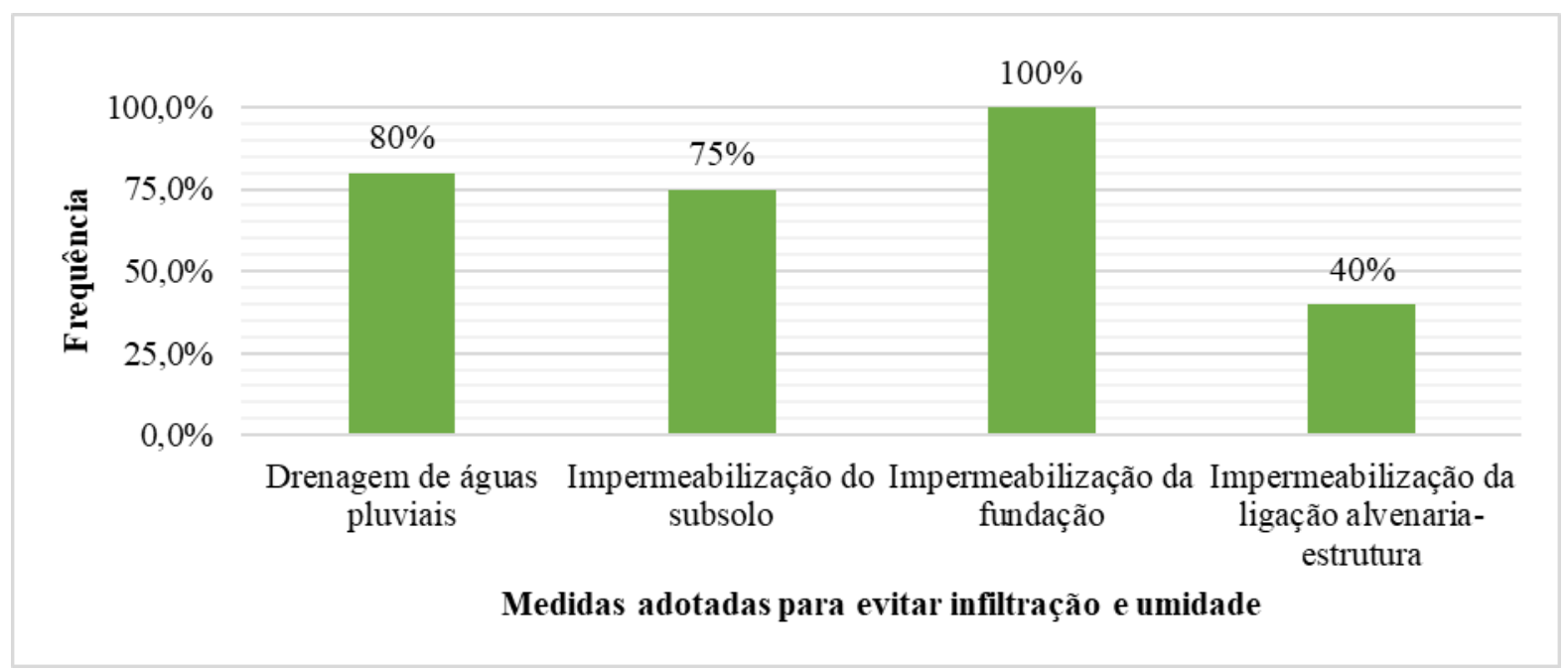

Figura 5 - Medidas adotadas para redução de impacto ambiental

Das cinco habitações consultadas, quatro apresentam subsolos. Três destas informaram que foi realizada a impermeabilização nessas áreas, de forma a evitar o contato de alvenarias e estrutura com a umidade proveniente do solo. Essa ação fornece maior habitabilidade e segurança às regiões de subsolo, que são mais sujeitas à presença de umidade excessiva. A única medida adotada em todas as obras avaliadas foi a impermeabilização da fundação. A alta frequência do emprego de medidas voltadas ao reforço da estanqueidade à água dos elementos estruturais ressalta a precaução dos construtores locais para garantir a manutenção das funções dos sistemas estruturais.

\subsection{Requisitos específicos dos sistemas estruturais}

Grande parte das questões referentes ao comprometimento do desempenho dos sistemas estruturais abordadas no questionário foram relatadas como não existentes em todas as obras consultadas. Apenas aspectos que não comprometem diretamente com a integridade do sistema estrutural foram dados como presentes em algumas edificações, e ainda assim apresentam-se em baixa incidência. Todos esses pormenores relacionam-se a possíveis desconfortos que podem ser gerados ao usuário, mas que não comprometem sua segurança física, conforme será exposto a diante.

Os problemas que foram apontados como não existentes em todas as habitações consultadas durante a pesquisa são:

- Instabilidade de elementos da estrutura;

- Deformação de elemento estrutural capaz de comprometer ou impedir o funcionamento de partes móveis das edificações, como por exemplo esquadrias, ou de instalações prediais;

- Existência de elemento estrutural com deformação excessiva, considerando-se os limites estabelecidos pela ABNT NBR 6118;

- Existência de elemento estrutural com fissuras de grande magnitude, considerando-se os limites estabelecidos pela ABNT NBR 6118.

Esses dados de caráter tão positivo podem representar duas realidades. A primeira seria a real ausência desses distúrbios nos elementos estruturais das habitações, o que indicaria que o nível de desempenho mínimo desses sistemas estruturais é de fato atingido. Porém, também há a possibilidade de que essas falhas não sejam relatadas apenas pelo fato de não terem sido detectadas pelas equipes técnicas. Dessa forma, eventuais problemas relacionados a esses aspectos não serão corrigidos antes da entrega das unidades habitacionais aos usuários, cabendo futuramente a eles a responsabilidade de detectar e providenciar reparo para eventuais danos provocados por falhas dessa natureza.

Apenas dois dos aspectos abordados no questionário foram relatados como existentes em algumas obras. Em duas das edificações avaliadas foi apontada a existência de elementos estruturais que continham grandes deformações, que apesar de não comprometerem a integridade da estrutura, são capazes de gerar desconforto ao usuário devido a ocasionais sensações de insegurança. Em um desses casos, foi reportada a existência de deformação excessiva em juntas de dilatação presentes em áreas de estacionamento. Já no outro caso, apresentaram-se vigas que possuíam deformações que, apesar de pequenas, já eram consideradas visíveis ao usuário. 
Por fim, em $80 \%$ dos casos não foi constatado que elementos estruturais provocassem deformações ou fissuras em elementos de construção vizinhos, tais como alvenarias, esquadrias e instalações elétricas ou hidrossanitárias, por exemplo. Isso indica que além do nível de desempenho mínimo do sistema estrutural ser atingido, os elementos estruturais não geram danos capazes de comprometer o desempenho de outros sistemas da edificação.

Já na obra em que foram observadas vigas com deformações consideradas excessivas, a ponto apenas de comprometer o conforto visual e psicológico do habitante, sem prejudicar a estabilidade desses elementos estruturais, foi relatada também a existência de fissuras no forro em áreas de alguns pavimentos. A presença dessas duas falhas na mesma obra pode ser um indício de relação causa e efeito, uma vez que as fissuras encontradas nos forros estão localizadas principalmente em áreas de contato desse revestimento com as vigas. Quando esses elementos deformam em magnitude maior do que o previsto, a integridade e o desempenho do forro são comprometidos.

Vale ressaltar que os aspectos aqui abordados são referentes às condições das habitações ainda durante a fase de execução das obras. Portanto, apesar de os dados obtidos serem considerados positivos em relação ao desempenho dos sistemas estruturais, não é assegurado que problemas dessa natureza não surjam futuramente, durante o uso e operação da edificação. Devido a esse fato, é de suma importância realizar inspeções prediais periódicas e manutenções.

\subsection{Manifestações patológicas no concreto armado}

Diante dos dados coletados, constatou-se que a incidência das principais manifestações patológicas que podem acometer estruturas de concreto armado é consideravelmente baixa nas edificações avaliadas. Verificou-se que o sistema estrutural de $60 \%$ dos empreendimentos era acometido por pelo menos uma patologia, e nenhum destes estaria comprometido por mais de dois problemas dessa natureza. Portanto, tem-se que em $40 \%$ dos casos, a estrutura estaria completamente livre dos prejuízos gerados pela existência de patologias.

Dentre as cinco variações de manifestações patológicas analisadas, apenas duas foram detectadas pelas equipes técnicas. Por fim, em nenhuma obra relatou-se a existência de outros tipos de patologia, além daqueles citados no questionário. A Figura 6 ilustra a frequência com que essas manifestações patológicas foram observadas na edificação avaliada.

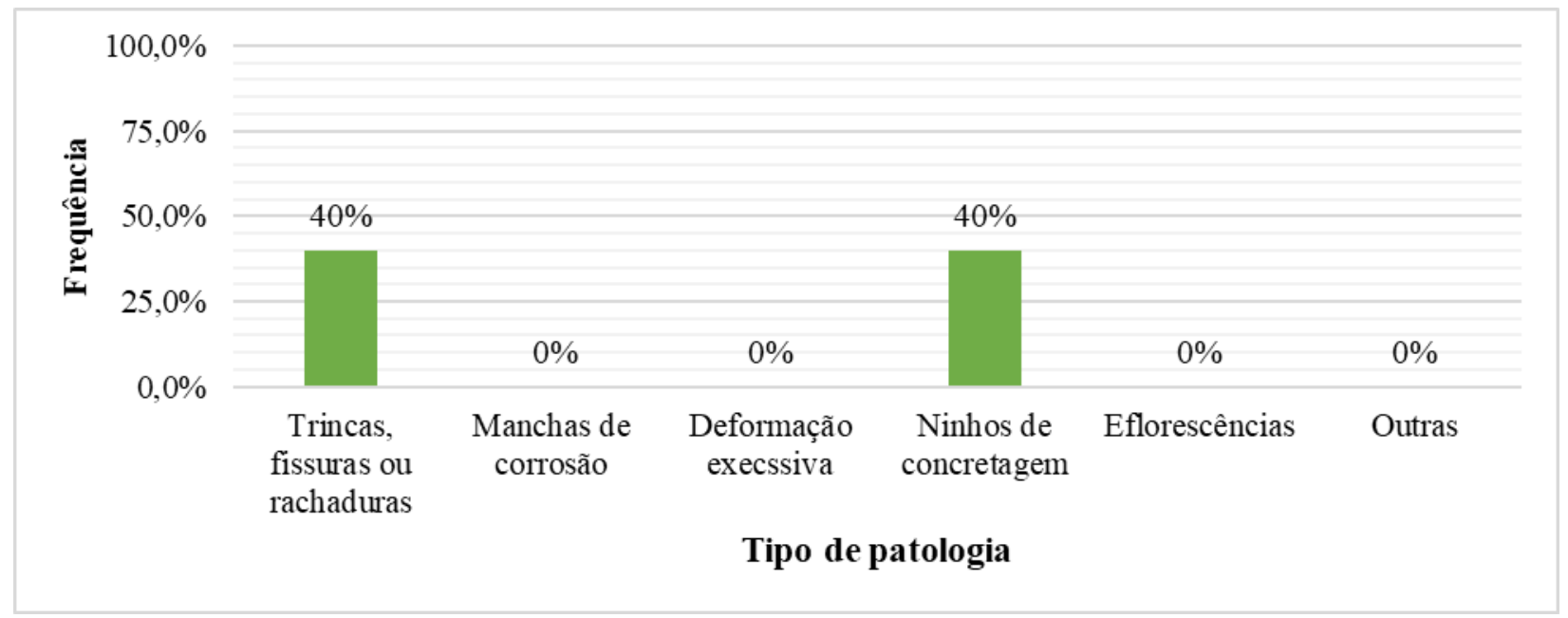

Figura 6- Manifestações patológicas em elementos estruturais durante a execução da obra

Das duas falhas dadas como existentes nos elementos estruturais desses empreendimentos, tem-se que em uma obra haviam somente ninhos de concretagem, enquanto em outra existiam apenas problemas relacionados a trincas, fissuras ou rachaduras, e por fim somente uma apresentou estes dois problemas simultaneamente.Tem-se também que em $60 \%$ dos casos, os responsáveis técnicos afirmaram que adotavam medidas evitar o surgimento de patologias.

Verifica-se que aqueles que apontaram a existência de manifestações patológicas de concreto armado em suas obras são os mesmos que aplicavam medidas de controle dessas manifestações. Vale ressaltar que todas as verificações realizadas acerca da existência de manifestações patológicas no concreto armado na amostra são referentes ao surgimento desses defeitos construtivos ainda durante o período de execução da obra. Logo, o fato de determinados edifícios não terem apresentado problemas dessa natureza no momento da pesquisa não descarta a possibilidade do surgimento de manifestações patológicas futuramente, seja antes da entrega do empreendimento aos proprietários ou durante o seu uso e operação. 


\section{CONSIDERAÇÕES FINAIS}

Diante do que foi exposto, é evidente que grande parte das recomendações da norma brasileira de desempenho habitacional, com ênfase nos quesitos relacionados aos sistemas estruturais compostos por concreto armado, são aplicadas nas edificações habitacionais multifamiliares de caráter vertical em execução no município de Juazeiro do Norte. De acordo com os resultados obtidos, tem-se que apenas alguns dos aspectos avaliados tem baixa aplicabilidade. Portanto, ao se considerar a localidade estudada, pode-se dizer que o nível de desempenho dos sistemas estruturais desse tipo de edificação é, de forma geral, satisfatório.

Porém não necessariamente esses resultados são reflexo do conhecimento dos profissionais a respeito dos critérios estabelecidos pela NBR 15575 (ABNT, 2013), quanto às condutas necessárias para garantir que o nível de desempenho mínimo dos sistemas estruturais seja atingido. No que diz respeito às estruturas de concreto armado, muitos dos aspectos que são expostos na norma de desempenho habitacional brasileira já foram de alguma maneira mencionados em normas prescritivas, como é o caso da NBR 6118/2014.

Além disso, comumente considera-se que os sistemas estruturais devem ser elaborados e executados com ampla eficiência, visto que erros grosseiros na composição desses componentes podem gerar danos irreparáveis à integridade de uma edificação. Dessa forma, torna-se mais comum os profissionais estarem atentos a diversas questões que findam na elevação do nível de desempenho da estrutura.

Portanto, é provável que os profissionais da construção civil da região já estivessem habituados em aplicar certos conjuntos de medidas necessárias durante o projeto e execução de uma edificação habitacional para permitir que a sua vida útil seja atingida. Isso reflete em uma adaptação mais rápida às especificações da nova norma e, consequentemente, em um prazo menor para que os benefícios gerados pela adoção dessas medidas sejam notados pelos usuários.

Os aspectos referentes às demais partes da norma de desempenho habitacional poderiam ser abordados em trabalhos futuros, a fim de verificar se essa mesma eficiência que foi observada em relação aos sistemas estruturais também se aplica aos demais componentes das edificações habitacionais do município de Juazeiro do Norte.

Também é importante destacar que ao decorrer deste trabalho, foram analisados apenas condomínios verticais. É plausível que os bons resultados obtidos durante a pesquisa estejam relacionados à dimensão das obras, uma vez que empreendimentos de maior porte tendem a ter maior valor agregado. Portanto, seria fundamental para os investidores que a qualidade do produto final fosse garantida, o que estimularia os construtores a manter o nível de desempenho acima do mínimo.

É provável que os resultados gerados ao se abordar edificações unifamiliares sejam distintos daqueles aqui apresentados, uma vez que, devido à maior amplitude de padrões de acabamento existentes nesse tipo de edificação na região, elas representam uma amostra mais heterogênea. Há a possibilidade de os critérios de desempenho mínimos não serem atingidos em uma considerável parcela dessa amostra, uma vez que encontrar casas cuja execução não conte com a participação ativa de uma equipe técnica competente ainda é bastante comum na região. Diante disso, a realização de um novo estudo que aborde esse tipo de habitação é válida.

Vale ressaltar que, pelo fato dos dados gerados durante a pesquisa serem oriundos da aplicação de um questionário, os resultados obtidos estão sujeitos à qualidade das respostas fornecidas pelas equipes técnicas entrevistadas. Como o acesso aos canteiros de obra e aos projetos dos empreendimentos durante a pesquisa foi restrito, a veracidade das respostas fornecidas não pôde ser atestada por outros meios. Dessa forma, baseia-se apenas na confiança de que os profissionais consultados teriam respondido o questionário de acordo com as condições reais das obras. Isso implica que os dados obtidos podem distorcer a realidade da amostra, devido às possibilidades de omissão, equívoco e fraude nas respostas fornecidas pelos entrevistados.

Devido a fatores como esse, torna-se sugestiva a realização de um trabalho futuro com objetivos similares, porém com foco na verificação de questões mais pontuais, que possam ser constatadas de forma direta pelo pesquisador, através da aplicação de um checklist.

\section{REFERÊNCIAS}

ASSOCIAÇÃO BRASILEIRA DE NORMAS TÉCNICAS. NBR 15575: Edificações Habitacionais - Desempenho Parte 1: Requisitos Gerais - Referências - Elaboração. Rio de Janeiro, 2013. 
ASSOCIAÇÃO BRASILEIRA DE NORMAS TÉCNICAS. NBR 6118/2014: Projeto de Estruturas de Concreto Procedimentos - Referências - Elaboração. Rio de Janeiro, 2014.

ASSOCIAÇÃO BRASILEIRA DE NORMAS TÉCNICAS. NBR 8681: Ações e Segurança nas Estruturas Procedimento. Rio de Janeiro, 2003.

BORGES, C. A. M. O conceito de desempenho das edificações e a sua importância para o setor da construção civil. Dissertação de Mestrado - Escola Politécnica da Universidade de São Paulo. São Paulo, 2008.

CBIC, Câmara Brasileira da Indústria da Construção. Desempenho de edificações habitacionais: Guia orientativo para atendimento à norma ABNT NBR 15575/2013. $2^{\mathrm{a}}$ ed. Brasília, Gadioli Cipolla Comunicação, 2013.

FRANÇA, A; MARCONDES, C.; ROCHA, F.; MEDEIROS, M; HELENE, P. Patologia das construções: uma especialidade na engenharia civil. São Paulo, Téchne, Revista de Tecnologia da Construção, PINI, v.174, Setembro, 2011.

Instituto de Pesquisa e Estratégia Econômica do Ceará (IPECE). Disponível em: <http://www2.ipece.ce.gov.br/atlas/capitulo1/11/139.htm>. Acessado em 07/06/2019. 